\title{
Assessment of postoperative risk of complications on inguinal hernioplasty and its relation to risk factors
}

1. Cirurgião-geral do Hospital da Cruz Vermelha, Curitiba, PR, Brasil. 2. Professor da Faculdade de Medicina da Universidade Positivo, Curitiba, PR, Brasil. 3. Médica residente em cirurgia geral no Hospital de Clínicas UFPR, Curitiba, PR, Brasil.

http://dx.doi.org/10.1590/1806-9282.66.5.623

\begin{abstract}
SUMMARY
INTRODUCTION: Abdominal wall hernias are a highly prevalent pathology, considering that 55 percent of the world population is affected by this disease at some point in their lives. As a large part of these patients present comorbidities, it is important to correlate the incidence of complications with the presence of previous pathologies.

OBJECTIVES: To evaluate whether the presence of comorbidities in patients submitted to inguinal hernioplasty increases the risk of acute and chronic complications in the postoperative period, as well as to explain which of these prior diseases present a greater association with the incidence of complications.

METHODS: This is a cross-sectional descriptive study carried out through the retrospective analysis of 373 medical records of patients submitted to open inguinal hernioplasty surgery between March and June 2017 at the General Surgery Service of the Cruz Vermelha Hospital - Paraná Branch, located in the City of Curitiba, state of Paraná, Brasil.

RESULTS: Of the 313 cases studied, the most prevalent comorbidities were: 107 patients with hypertension (34.19\%), 52 smokers (16.61\%), 30 cases with diabetes (9.58\%), 14 with hypothyroidism (4,47\%) and 10 with COPD (3.19\%). Regarding the total of the sample evaluated, 130 patients $(41.53 \%)$ did not present any comorbidity. When evaluating the complications, there were 49 cases (15.65\%) of complications in the early postoperative period and 9 cases (2.88\%) of chronic complications. The comorbidities that presented significant statistical influence $(p<0.05)$ on the incidence of acute complications were hypertension $(p=0.02927)$ and smoking $(p=0.03196)$. CONCLUSION: It is important to note the presence of acute postoperative complications of inguinal hernioplasty in patients who have hypertension or smoke, high prevalence diseases.
\end{abstract}

KEYWORDS: Hernia, inguinal. Herniorrhaphy. Postoperative complications.

\section{INTRODUCTION}

Inguinal hernioplasty is the most commonly performed surgical procedure in abdominal wall surgery, with 80,000 surgeries performed annually in Great Britain, 100,000 in France and 700,000 in the US ${ }^{1}$. It is noteworthy that there is a higher prevalence of right unilateral hernia and in both adults and children, the indirect form is more common than the direct form. There is a predominance of males, and the delay in performing the surgery may progress to incarcerated hernia, increasing the rate of complications. Several surgical techniques have been described in the literature for the correction of inguinal hernia, among

DATE OF SUBMISSION: 29-Nov-2019

DATE OF ACCEPTANCE: 08-Dec-2019

CORRESPONDING AUTHOR: Oona Tomiê Daronch

Rua Coronel Dulcídio, 1255, Curitiba, PR, Brasil - 81280-330

Tel: +55 41 98897-3893 / +55 413232-6088

E-mail: oona.daronch@yahoo.com.br 
which the Lichtenstein technique stands out in this work, as it is the most used and in which the mesh is used, preferably of polypropylene, which, being a multifilament, reduces the risk of exacerbated healing, as evidenced in Figure 1. Several risk factors influence the outcome of the long-term surgery, which can be modifiable or not modifiable. The first group includes obesity, smoking and poorly controlled hypertension. In this last set of comorbidities, liver cirrhosis, age, pro-inflammatory medical conditions, peripheral vascular disease and anxious depressive disorders stand out. The analysis of these preoperative risk factors can assist in the evaluation of the post-surgical result.

FIGURE 1. INGUINAL HERNIOPLASTY SURGERY USING THE LICHTENSTEIN TECHNIQUE, SHOWING THE PLACEMENT OF THE MESH AND OPENING FOR THE PASSAGE OF THE SPERMATIC CORD 2

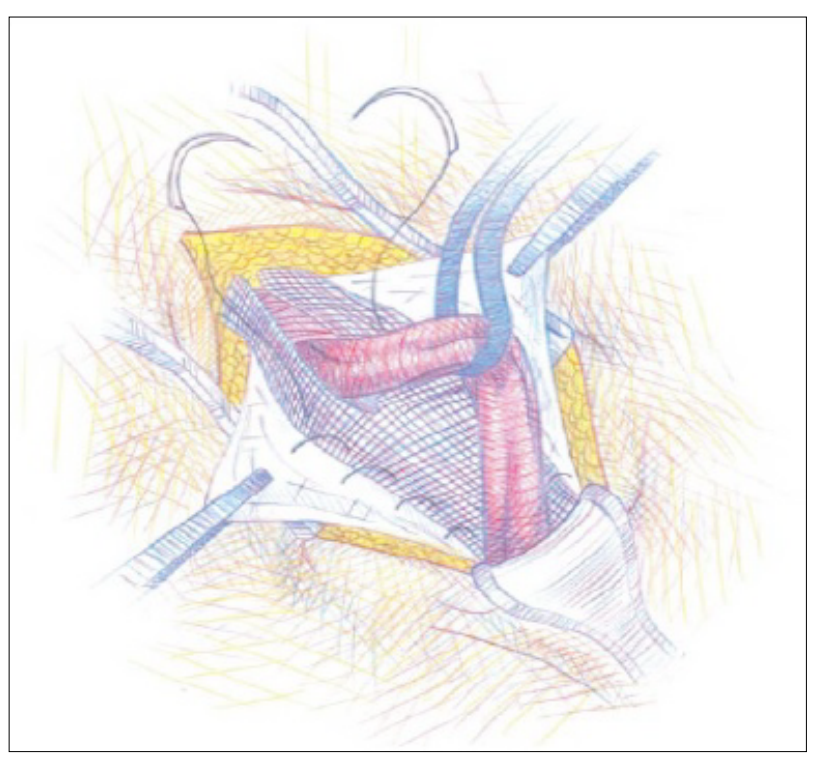

\section{METHODS}

This is a cross-sectional descriptive study carried out between March and June 2017, at the General Surgery Service of Hospital Cruz Vermelha - Paraná Branch, located in the city of Curitiba, state of Paraná, Brasil. Initially, patients who underwent inguinal hernioplasty using the original Lichtenstein technique under any anesthesia were selected, according a book of records of surgeries performed at this service, covering the period between January 2015 and April 2017.

By the number of the medical record obtained in the record book, an electronic medical record review was performed via Tasy and an electronic form was completed via Google Drive, in which patients were grouped by age, sex, laterality of the inguinal hernia, recurrences, comorbidities, early complications (one month) and late (more than one month).

The exclusion criteria were medical records that did not present minimum information for the correct completion of the form.

This work was submitted and approved by the Ethics Committee of the Hospital Cruz Vermelha - Paraná Branch under the registration number 8737264767. The names or any other data of the patients were not revealed, being the responsibility of these researchers the medical confidentiality according to the ethical and moral rules promulgated by the Code of Medical Ethics of the Federal Council of Medicine.

The results of quantitative variables were described by means, medians, minimum values, maximum values and standard deviations. Qualitative variables will be described by frequencies and percentages. The Chisquare test was used to assess possible associations. Values of $p<0.05$ indicated statistical significance. The data were analyzed using the IBM SPSS Statistics v.20 computer program.

\section{RESULTS}

\section{Sample profile}

This study evaluated 313 cases of inguinal hernioplasty using the open technique performed during the three-year period at our service. In 13 cases (4.15\%) there was no mesh placement due to the presence of infection, and in two of these cases (15.38\%) the inguinal hernia was incarcerated. Regarding the profile of the sample, it consisted of 30 women (9.58\%) and 283 men $(90.42 \%)$. There were 111 cases $(35.46 \%)$ of left hernioplasty, 154 cases (49.21\%) of right hernioplasty and 48 cases $(15.33 \%)$ of bilateral hernioplasty, according to Chart 1 . The mean age of the patients was 56.26 years old $(\mathrm{SD}=11.38)$. Regarding the average length of hospitalization, it was one day. There were 288 patients (92.01\%) who were hospitalized for just one day; 11 (3.51\%) were hospitalized for two days; five $(1.60 \%)$ were hospitalized for three days; two for four days (0.64\%); and one stayed ten days $(0.32 \%)$ due to incarcerated hernia, as shown in Graph 2. In 33 patients $(10.54 \%)$ the hernia was already recurrent. of these, in 30 cases it was the second recurrence (9.58\%); in two cases it was the third time (0.64\%); and in one case $(0.32 \%)$ it was the fourth time or more.

\section{Main comorbidities}

The incidence of comorbidities was calculated 
jointly, that is, some patients had more than one comorbidity. Of the 313 patients, there were 30 cases with diabetes (9.58\%), 107 with Systemic Hypertension (34.19\%), 52 smokers (16.61\%), 16 with mixed anxiety-depressive disorder - MADD (5.11\%), three with cancer (0.96\%), three with obesity (0.96\%), ten with COPD (3.19\%), 14 with hypothyroidism (4.47\%), one with liver cirrhosis $(0.32 \%), 17$ (5.43\%) with cardiac changes (previous MI, HF, arrhythmias), three with dyslipidemia (0.96\%), immunosuppression in four cases $(1.28 \%)$ - three of them with HIV. In relation to the total sample studied, 130 patients (41.53\%) did not present any comorbidity.

\section{Early or late postoperative complications}

of the total of 313 patients who underwent open inguinal hernioplasty surgery, there were 49 (15.65\%) complications in the early postoperative period. Of these, the main ones were post-spinal anesthesia headache in one case $(2.04 \%)$, a cyst in the inguinal region (2.04\%), a slight dehiscence of the surgical wound (2.04\%), two cases of severe pain $(4.08 \%)$, two

GRAPH 1. LOCATION OF INGUINAL HERNIA IN PATIENTS WHO UNDERWENT INGUINAL HERNIOPLASTY

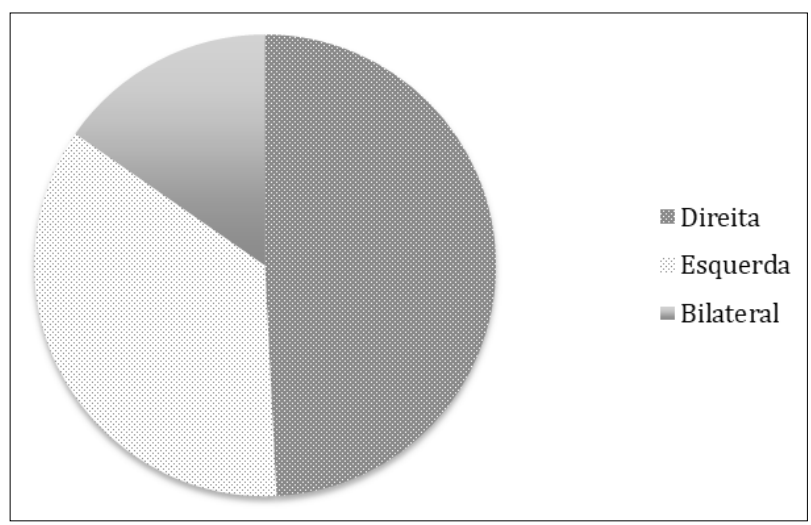

GRAPH 2. LENGTH OF HOSPITAL STAY OF PATIENTS UNDERGOING INGUINAL HERNIOPLASTY

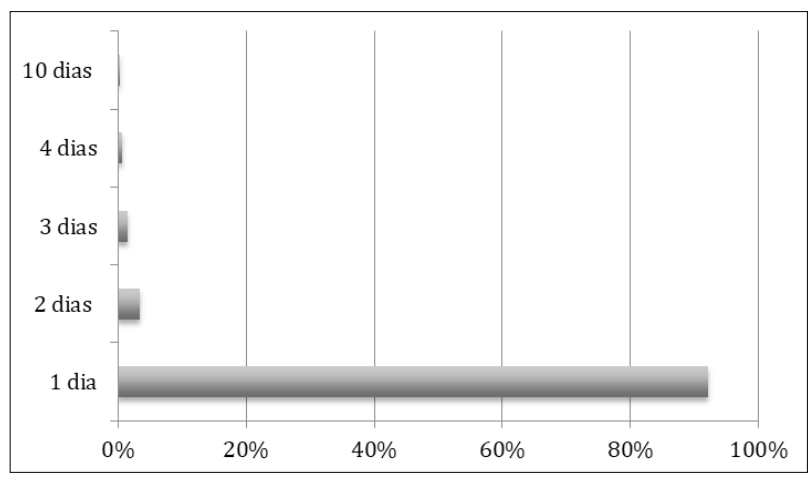

situations of scrotal edema (4.08\%), two cases of major edema (4.08\%), one case of fever (2.04\%), nine bruises (18.37\%), two incarcerated hernias (4.08\%), eight infections $(16.32 \%)$, one case of orchialgia (2.04\%), four orchitis (8.16\%), one case of bleeding (2.04\%) and 11 seromas (22.45\%). Table 1 explains the acute complications. In the case of complications in the late postoperative period, there were nine cases $(2.88 \%)$, of which the following stand out: chronic pain in two cases $(22.22 \%)$, scrotal edema in one case $(11.11 \%)$, two cases of inguinodynia (22.22\%), one paresis at the surgery site (11.11\%), bilateral recurrence (11.11\%) and one unilateral recurrence (11.11\%). Chart 3 quantifies chronic complications.

Profile of complications in the analyzed sample

Of the 30 women, two had complications in the immediate postoperative period (6.67\%), one of which

TABLE 1. ABSOLUTE AND RELATIVE FREQUENCIES OF ACUTE COMPLICATIONS

\begin{tabular}{l|l|l} 
Acute complication & $\begin{array}{l}\text { Absolute } \\
\text { frequency }\end{array}$ & $\begin{array}{l}\text { Relative fre- } \\
\text { quency (\%) }\end{array}$ \\
\hline Post-spinal anesthesia headache & 1 & 2.04 \\
\hline Inguinal cyst & 1 & 2.04 \\
\hline Mild surgical wound dehiscence & 1 & 2.04 \\
\hline Fever & 1 & 2.04 \\
\hline Orchialgia & 1 & 2.04 \\
\hline Bleeding & 1 & 2.04 \\
\hline Severe pain & 2 & 4.08 \\
\hline Scrotal edema & 2 & 4.08 \\
\hline Major edema & 2 & 4.08 \\
\hline Imprisoned hernia & 2 & 4.08 \\
\hline Orchitis & 4 & 8.16 \\
\hline Infection & 8 & 16.32 \\
\hline Bruise & 9 & 18.37 \\
\hline Seroma & 11 & 22.45 \\
\hline
\end{tabular}

GRAPH 3. ABSOLUTE FREQUENCY OF THE MAIN CHRONIC COMPLICATIONS

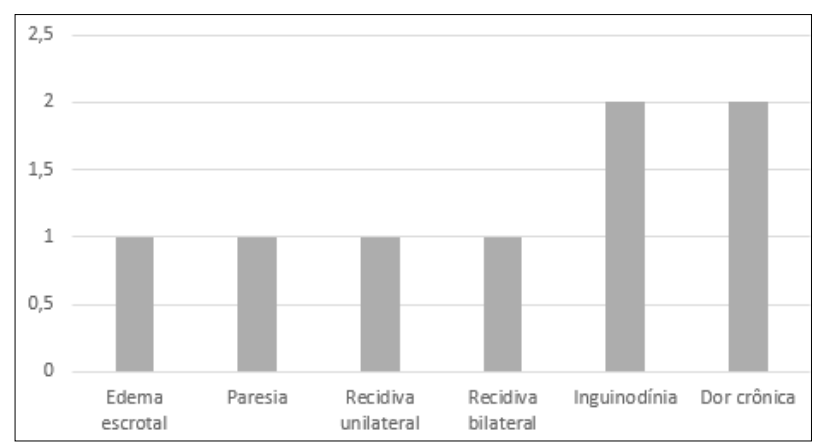


was infection and the other, hematoma. Of the 30 women, one (3.33\%) presented complications in the late postoperative period, which was local pain. Of the 283 men, 47 (16.6\%) had complications in the immediate postoperative period and eight (2.83\%) had complications in the late postoperative period. There were more acute complications in men $(p=0.2357)$ and a higher incidence of chronic complications in women ( $>$ 0.99999999). In neither case there was statistical significance $(p<0.05)$ in relation to the higher incidence of early or late postoperative complications in men or women.

Of the total of 130 patients (41.53\%) who did not present any comorbidity, $11(8.46 \%)$ presented complications in the immediate postoperative period and three (2.31\%) presented complications in the late postoperative period. Of the 183 patients who had some comorbidity (58.47\%), 38 had complications in the immediate postoperative period (20.76\%) and nine had complications in the late postoperative period (4.8\%). Regarding the group without comorbidities and the group with comorbidities, when comparing the incidence of acute complications, the $p$ was 0.004148 ; for late complications, $p$ was 0.3778 . The presence of comorbidities affected the immediate postoperative period, but not the late postoperative period.

Of the 202 patients under 65 years old (including those who were 65 years old), 30 (14.85\%) had acute complications and six (2.97\%) had chronic complications. Of the 110 patients over 65 years old, 19 had acute complications (17.27\%) and three had chronic complications (2.73\%). The $p$ in both groups (first group including patients under 65 years old and second group including patients over 65 years old) for acute complications was 0.6836 , and for chronic complications was $>0.99999999$.

Regarding the 278 patients without recurrent hernia, 45 had acute complications (16.19\%) and five had chronic complications (1.80\%). Of the 33 patients with recurrent hernia, four had acute complications (12.12\%) and four had chronic complications (12.12\%). The $p$ for acute complications (comparing patients who had no recurrent hernia and patients who had recurrent hernia) was 0.7561 , and for chronic complications was 0.01822 .

A comparison was made between patients with recurrent inguinal hernia with comorbidities and patients with recurrent inguinal hernia without comorbidities. There were nine patients with recurrent hernia without comorbidities, and of these, two had acute complications (22.22\%) and two had chronic complications (22.22\%). In a total of 24 patients with recurrent hernia with comorbidities, two of them had acute complications (8.33\%) and two had chronic complications (8.33\%). The $p$ for acute and chronic complications was the same $(p=0.5903)$.

The main comorbidities analyzed were diabetes in 30 cases $(9.58 \%)$, hypertension in 107 (34.18\%), smoking in 52 (16.61\%), immunosuppression in four (1.28\%), anxiety-depressive disorder in 16 (5.11\%), obesity in three (0.96\%), cardiac disorders in 17 (5.43\%), COPD in ten (3.19\%) and hypothyroidism in 14 (4.47\%), according to Graph 4. It was noticed that these did not present a significant relationship with chronic complications, however, hypertension and smoking were relevant in the incidence of acute complications, as shown in Table 2 below.

\section{DISCUSSION}

According to current literature, hernias " "correspond to the partial or total protrusion of a viscera or organ contained in a bag with peritoneal lining outside the abdominal wall through a defect in the muscle-aponeurotic wall". Hernias can occur in different positions: umbilical (10\%), epigastric (6\%), incisional (10\%), femoral (5\%) or the most common one, inguinal (69\%). The only definitive treatment available for hernias is surgical. Despite the large number of techniques available for treatment, the use of meshes has been recommended in the surgical correction of this pathology ${ }^{3}$. In our study, the mesh was placed in 300 cases (95.85\%), except for those in which there was infection or when the hernia was infected, since in these cases there is less benefit in placing the mesh and a large increase in morbidity.

GRAPH 4. MAIN COMORBIDITIES FOUND IN RELATIVE FREQUENCY (\%)

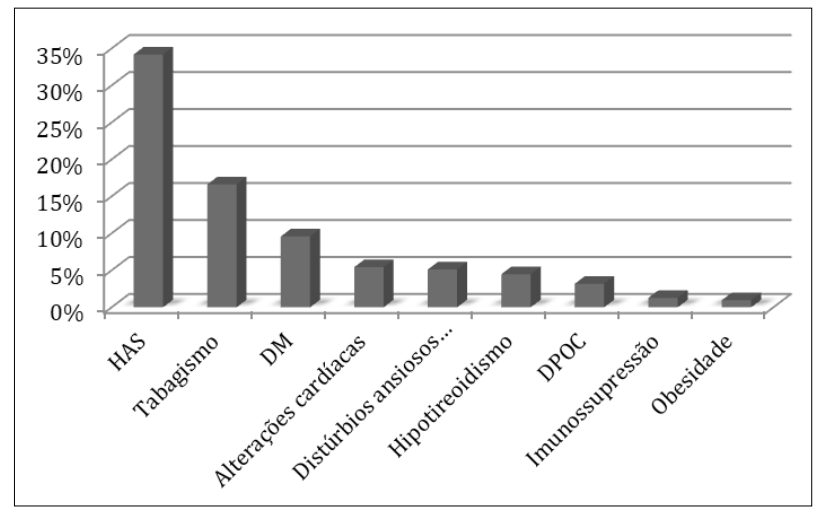


TABLE 2. MAIN COMORBIDITIES AND THEIR RELATIONSHIP WITH ACUTE AND CHRONIC COMPLICATIONS

\begin{tabular}{l|l|l|l|l}
\hline Comorbidities & Acute complications & $\mathrm{p}$ & Chronic complications & $\mathrm{p}$ \\
\hline Diabetes & $7(23.33 \%)$ & 0.3369 & $3(0.1 \%)$ & 0.09006 \\
\hline Hypertension & $24(22.43 \%)$ & 0.02927 & $4(3.74 \%)$ & $>0.9999999$ \\
\hline Smoking & $14(26.92 \%)$ & 0.03196 & $1(1.92 \%)$ & $>0.9999999$ \\
\hline Immunosuppression & 0 & - & 0 & - \\
\hline Anxiety-depression disorder & $3(18.75 \%) 0.5500$ & - & $1(6.25 \%)$ & 0.7606 \\
\hline Obesity & $1(33.33 \%)$ & - & 0 & - \\
\hline Cardiac alterations & $3(17.65 \%)$ & - & 0 & - \\
\hline COPD & 0 & - & 0 & - \\
\hline Hypothyroidism & $2(14.29 \%)$ & $>0.9999999$ & $1(7.14 \%)$ & 0.6824 \\
\hline
\end{tabular}

There are techniques that use only primary aponeurotic sutures - which must be tension-free - and techniques that use synthetic prostheses, the meshes, which is the case in this study ${ }^{4}$. Inguinal hernias are more common indirect, unilateral, on the right side and in men, with the risk of presenting this change throughout life being $27 \%$ in men and $3 \%$ in women ${ }^{5}$. The epidemiological data from the studies already carried out coincide with this research, since in 263 cases $(84.02 \%)$ the hernias were unilateral, in 152 patients (48.56\%) they occurred on the right, and the study sample consisted of 283 men (90.42\%), against 30 women (9.58\%). Bilateral ones are rarer (they affect about $12 \%$ of patients), with direct and mixed ones being more frequent than indirect ones ${ }^{6}$. Regarding bilateral hernias, there was an incidence of 48 cases (15.33\%).

Risk factors that are useful in predicting complications in an adult patient with an inguinal hernia include old age, short duration, femoral hernia and coexisting medical disease ${ }^{7}$. A study carried out in 2013, covering patients over 50 years old and who underwent inguinal hernioplasty, showed that the short-term morbidity of patients undergoing tension-free surgery was: postoperative urinary retention $(1.75 \%)$, infection at the surgical site (superficial wound infection) (1.75\%) and scrotal edema (3.5\%) ${ }^{7}$. Making a comparison with our study, it is noticed that there was a higher incidence of immediate complications in patients older than 65 years of age, in comparison with the group of patients who are not elderly, but there was no statistically significant correlation $(p=$ 0.6836). Regarding chronic complications, there was neither a higher incidence in the elderly population nor statistical significance ( $p>0.99999999)$. It was also not possible to verify that elderly patients with comorbidities had a higher rate of acute complications ( $p=0.2359)$ compared to a group of elderly people without comorbidities, or of chronic complications $(p=0.5365)$. On the other hand, the study shows that the population with comorbidities who underwent open inguinal hernioplasty has a higher risk of developing acute complications $(\mathrm{p}=0.004148)$ compared to patients without comorbidities who underwent the same surgery, but there is no statistically significant increase in the incidence of chronic complications ( $p$ $=0.3778$ ).

According to studies previously carried out, the main complications in the immediate postoperative period include pain (27.7\%), seroma (1.5\%), infection (1.5\%) and ecchymosis (1.5\%), but most patients (61.5\%) have no complications during this period ${ }^{8}$. These data are not very similar to the present study, since from the sample studied, there were two cases of severe pain (4.08\%), 11 cases of seroma (22.45\%), eight cases of infection (16.32\%) and nine cases of hematoma (18.37\%). Among the other acute complications in our research, the following stand out: post-spinal anesthesia headache (2.04\%), one inguinal cyst $(2.04 \%)$, one mild surgical wound dehiscence (2.04\%), two cases of scrotal edema (4.08\%), two cases of major edema (4.08\%), one case of fever (2.04\%), two cases of incarcerated hernia $(4.08 \%)$, one case of orchialgia $(2.04 \%)$, four cases of orchitis (8.16\%) and one case of bleeding (2.04\%).

In the case of chronic complications in the late postoperative period, studies show a lower complication rate (5\%), with a predominance of inguinodynia (3\%) and local burning $(2 \%)^{8}$. In the sample analyzed, there were 9 cases $(2.88 \%)$ of chronic complications, of which chronic pain was more relevant in 2 cases (22.22\%), scrotal edema in 1 case (11.11\%), 2 cases of inguinodynia $(22.22 \%)$, one paresis at the surgery site (11.11\%), one bilateral recurrence (11.11\%) and one unilateral recurrence (11.11\%). It was also noticed that patients who presented recurrent hernia had higher rates of complications in the late postoperative period $(p=0.01822)$. 
Literature data show that the presence of comorbidities is a factor that significantly influences the incidence of postoperative complications in inguinal hernioplasty ${ }^{9-21}$. Diabetes appears to increase the risk of postoperative complications within 30 days of inguinal hernia surgery, especially for complicated diabetes, but this disease does not appear to increase the long-term risk of reoperation for recurrence ${ }^{9}$. In contrast, this study did not show an increase in the incidence of acute $(p=0.3369)$ or chronic $(p=0.09006)$ complications in diabetic patients compared to non-diabetic individuals.

In addition to diabetes, other comorbidities quite present in the population, such as hypertension, smoking, immunosuppression, anxiety-depressive disorder, obesity, cardiac disorders, COPD and hypothyroidism were also analyzed. It was noticed that for chronic complications, none of them influenced significantly statistically ( $p>0.05)$, but for acute complications, the presence of hypertension $(p=0.02927)$ and also smoking $(p=0,03196)$ was decisive for the increase of these complications.

\section{CONCLUSION}

Inguinal hernia is one of the main surgical pathologies present in adult patients, and it is essential to know not only the surgical technique, but mainly the surgical clinic, in relation to the aspects involved in the preoperative and also its outcome. Among these issues, the study of the comorbidities of patients undergoing inguinal hernioplasty stands out, since the present study highlighted that the presence of systemic arterial hypertension and smoking have a statistically significant influence on the incidence of acute postoperative complications. Adequate control of these issues in the preoperative period and adequate guidance to the patient can help in the optimization of the surgical process of correcting inguinal hernia.

\section{RESUMO}

INTRODUÇÃO: As hérnias da parede abdominal constituem uma patologia de alta prevalência; 55\% da população mundial é acometida por essa enfermidade em algum momento de suas vidas. Como grande parte desses pacientes apresenta comorbidades, torna-se importante correlacionar a incidência de complicações com a presença de patologias prévias.

OBJETIVOS: Avaliar se a presença de comorbidades no paciente submetido a hernioplastia inguinal aumenta o risco de complicações agudas e crônicas no pós-operatório, bem como explicitar quais dessas doenças prévias apresentam maior associação com a incidência de complicações.

METODOLOGIA: Trata-se de um estudo transversal descritivo realizado por meio da análise retrospectiva de 313 prontuários dos pacientes submetidos à cirurgia de hernioplastia inguinal aberta, entre março e junho de 2017, no Serviço de Cirurgia Geral do Hospital Cruz Vermelha - Filial Paraná, localizado na cidade de Curitiba, estado do Paraná, Brasil.

RESULTADOS: Dos 313 casos estudados, as comorbidades mais prevalentes foram: 107 pacientes com HAS (34,19\%), 52 com tabagismo (16,61\%), 30 casos com diabetes (9,58\%), 14 com hipotireoidismo (4,47\%) e 10 com DPOC (3,19\%). Em relação ao total da amostra avaliada, 130 pacientes (41,53\%) não apresentaram nenhuma comorbidade. Ao avaliar as complicações, houve 49 casos (15,65\%) de complicações no pós-operatório precoce e nove casos (2,88\%) de complicações crônicas. As comorbidades que apresentaram influência significativamente estatística $(p<0,05)$ na incidência de complicações agudas foram HAS ( $p=0,02927)$ e tabagismo $(p=0,03796)$.

CONCLUSÃO: Percebe-se correlação importante entre a presença de complicações agudas no pós-operatório de hernioplastia inguinal nos pacientes que apresentam HAS ou tabagismo, doenças de alta prevalência.

PALAVRAS-CHAVE: Hérnia inguinal. Herniorrafia. Complicações pós-operatórias.

\section{REFERENCES}

1. Grossi JV, Cavazzola LT, Breigeiron R. Inguinal hernia repair: can one identify the three main nerves of the region? Rev Col Bras Cir. 2015;42(3):149-53.

2. Goulart A, Martins S. Hérnia inguinal: anatomia, patofisiologia, diagnóstico e tratamento. Rev Port Cir. 2015;33:25-42.

3. Mizrahi H, Parker MC. Management of asymptomatic inguinal hernia: a systematic review of the evidence. Arch Surg. 2012;147(3):277-81.
4. Naveen N, Srinath R. A comparative study between modified Bassini's repair and Lichtenstein mesh repair (LMR) of inguinal hernias in rural population. J Clin Diagn Res. 2014;8(2):88-91.

5. Primatesta P, Goldacre MJ. Inguinal hernia repair: incidence of elective and emergency surgery, readmission and mortality. Int J Epidemiol. 1996;25(4):835-9. 
6. Maciel GSB, Simões RL, Carmo FPT, Garcia IWR, Paulo DNS. Resultados da herniorrafia inguinal bilateral simultânea pela técnica de Lichtenstein. Rev Col Bras Cir. 2013;40(5):370-3.

7. Shyam DC, Rapsang AG. Inguinal hernias in patients of 50 years and above. Pattern and outcome. Rev Col Bras Cir. 2013;40(5):374-9.

8. Malik AM, Khan A, Talpur KA, Laghari AA. Factors influencing morbidity and mortality in elderly population undergoing inguinal hernia surgery. Pak Med Assoc. 2010;60(1):45-7.

9. Mansouri M, Ekjam S, Hudairi A, Sannussi OI, Fakheri A. Emergency abdominal surgery in Libyan elderly patients. Sci Med J. 2005;17(3):57-65.

10. Gautam PV, Litake MM. A comparative study between STOPPA repair and Lichtenstein MESH repair in the treatment of bilateral inguinal hernia. Indian | Basic Appl Med Res. 2017;6(2):569-74.

11. Paajanen $\mathrm{H}$. Do absorbable mesh sutures cause less chronic pain than nonabsorbable sutures after Lichtenstein inguinal herniorraphy? Hernia. 2002;6(1):26-8

12. Minossi JG, Minossi WV, Silva AL. Manejo da dor inguinal crônica pós-hernioplastia (inguinodinia). Rev Col Bras Cir. 2011;38(1):59-65.

13. Vianna JLCM, Silva AL, Alves AS, Oliveira CA, Vieira Júnior A. Comparação entre as técnicas de Shouldice e Falci-Lichtenstein, no tratamento das hérnias inguinais em homens. Rev Col Bras Cir. 2004;31(2):117-23.
14. Hellspong G, Gunnarsson U, Dahlstrand U Sandblom G. Diabetes as a risk factor in patients undergoing groin hernia surgery. Langenbecks Arch Surg. 2017;402(2):219-25.

15. Bugada D, Lavand'homme P, Ambrosoli AL, Cappelleri G, Saccani Jotti GM Meschi $T$, et al. Effect of preoperative inflammatory status and comorbidities on pain resolution and persistent postsurgical pain after inguinal hernia repair. Mediators Inflamm. 2016;2016:5830347.

16. Rühling V, Gunnarsson U, Dahlstrand U, Sandblom G. Wound healing following open groin hernia surgery: the impact of comorbidity. World I Surg 2015;39(10):2392-9.

17. Lagoo J, Wilkinson J, Thacker J, Deshmukh M, Khorgade S, Bang R. Impact of anemia on surgical outcomes: innovative interventions in resource-poor settings. World J Surg. 2012;36(9):2080-9.

18. Klinge $U$, Weyhe $D$. Hernia surgery: minimization of complications by selection of the "correct mesh". Chirurg. 2014;85(2):105-11.

19. Compagna R, Rossi R, Fappiano F, Bianco T, Accurso A, Danzi M, et al. Emergency groin hernia repair: implications in elderly. BMC Surg. 2013;13(Suppl. 2):S29

20. Ozdemir T, Arıkan A. Postoperative apnea after inguinal hernia repair in formerly premature infants: impacts of gestational age, postconceptional age and comorbidities. Pediatr Surg Int. 2013;29(8):801-4.

21. Yunis |. Critical issues in groin hernia management. Surg Technol Int. 2009;18:119-24. 